\title{
Stigma and Migraine: Developing Effective Interventions
}

\author{
Simy K. Parikh ${ }^{1}$ Joanna Kempner ${ }^{2} \cdot$ William B. Young $^{1}$ \\ Accepted: 14 July 2021 / Published online: 6 December 2021 \\ (c) The Author(s), under exclusive licence to Springer Science+Business Media, LLC, part of Springer Nature 2021
}

\begin{abstract}
Purpose of Review Migraine and other primary headache disorders do not receive adequate research funding, medical resources, or other forms of structural support relative to their prevalence and the disability they cause. In recent research, scholars have argued that stigma associated with headache disorders explains some of this discrepancy.

This review will discuss (1) the factors contributing to stigma toward migraine and other primary headache disorders, (2) how structural and enacted stigma may perpetuate individual disability, (3) the impact of internalized stigma, and (4) interventions to mitigate stigma toward headache disorders with an emphasis on outcome monitoring. The review will also propose new areas of stigma research in need of further investigation.

Recent Findings Recent research shows that discrimination can exacerbate chronic pain.

Summary Stigma profoundly affects everything from the allocation of federal research funds and healthcare resources to individual patients' self-efficacy and ability to care for themselves. Understanding the stigma of migraine and learning how to develop effective interventions to mitigate this stigma will increase access to appropriate migraine care, improve healthcare providers' ability to care for their migraine patients, and help advocates reverse policies that discriminate against those with migraine. It is important to closely monitor outcomes of anti-stigma efforts for both positive and negative consequences and take note of outcomes and "lessons learned" from anti-stigma campaigns for other diseases.
\end{abstract}

Keywords Migraine $\cdot$ Headache $\cdot$ Stigma $\cdot$ Stigmatization $\cdot$ Discrimination $\cdot$ Stereotypes

\section{Introduction}

According to the World Health Organization's (WHO) estimates, migraine and other primary headache disorders are the second leading cause of years lived with disability in the world [1]. Nevertheless, government funding for research on migraine is miniscule and access to medical care and

This article is part of the Topical Collection on Psychological and Behavioral Aspects of Headache and Pain

William B. Young

william.young@jefferson.edu

Simy K. Parikh

simy.parikh@jefferson.edu

Joanna Kempner

jkempner@sociology.rutgers.edu

1 Jefferson Headache Center, Department of Neurology, Thomas Jefferson University, Philadelphia, PA 19107, USA

2 Department of Sociology, Institute of Health, Health Care Policy, and Aging Research, Rutgers University, The State University of New Jersey, New Brunswick, NJ 08901, USA treatment remains limited [2-4]. Recent research suggests that stigma associated with migraine and other headache disorders might explain much of this disparity.

In response, multiple migraine and headache advocacy organizations have launched programs designed to reduce headache-related stigma in the hopes of increasing resources. Unfortunately, advocates have little evidence from which to build their interventions. Only a few studies have examined stigma in relationship to head pain and, of those, almost all have focused on migraine [5-8•].

Fortunately, the headache community need not start from scratch, as researchers and advocates in other disease arenas have been working to reduce stigma for decades. For example, social scientists have long studied health-related stigma in relation to a broad range of diagnoses, including mental illness, addiction, and HIV [9-12]. Other research has focused specifically on stigma related to neurological diseases [7, 13-16]. Epilepsy, for example, has long been of interest to stigma researchers who sought to understand how its historical association with demonic possession might affect contemporary practice $[17,18]$. This 
review sifts through the broader literature on health-related stigma in order to draw up a list of "lessons learned" that may guide the headache community as we design future migraine-specific stigma research and new, innovative stigma interventions.

\section{Stigma Theory}

Stigma in the social sciences describes any socially undesirable or discrediting attribute derived from markers of identity. These markers include race, nationality or ethnicity, "blemishes of character," such as a criminal record, and indications of disease or biological "deformities," such as leprosy, amputations, or mental illness [19]. Because stigma has important social consequences for those who are marked, contemporary scholarship has focused on stigmatization, or the social process in which labeling occurs. In stigmatization, some gain power by stigmatizing others as different, which in turn, enables those in power to justify the exclusion and stripping of resources of those they have devalued. Stigma, therefore, enforces unjust hierarchies because it strips the stigmatized of social, economic, political, and arguably, personal, power $[9,20,21]$.

Our review focuses on three primary forms of stigma: public, structural, and internalized stigma. Public stigma refers to negative attitudes and stereotypes circulating in the general public [21]. Structural stigma occurs when public stigma and the negative attitudes and stereotypes it entails are embedded into policies, laws, and organizational practices [21]. Finally, internalized stigma occurs when individuals begin to absorb and believe the negative stereotypes and assumptions made about their stigmatized condition. This form of stigma can devastate individuals' self-esteem, produce psychological distress, and exacerbate and produce additional ill-health [21]. Each of these forms of stigma contributes to poor health outcomes for those who are stigmatized. In fact, scholars have theorized that stigma, itself, ought to be considered a fundamental cause of disease, given how detrimental it can be to physical and mental health [9, 20, 21].

\section{Public Stigma and Migraine}

People with migraine are frequently labeled with stigmatizing stereotypes. Migraine labels documented in Kempner's [22•] book Not Tonight include baby, whiner, malingerer, pill popper, hypochondriac, hysterical, drug-seeking, lazy, weak-willed, neurotic, high-strung, or a person incapable of handling stress [22•]. These colloquial meanings regularly appear in jokes about migraine, in newspaper headlines that use migraine or headache as a metaphor for everyday annoyances and irritations, and in everyday parlance [22•].

Migraine's cultural associations with weakness and hysteria can be traced to early eighteenth-century Britain, when healthcare professionals began to describe migraine as a problem that only affected people in the socioeconomic upper class who had particular qualities associated with a "sensitive" or nervous personality: the scholarly, the delicate, the nervous, and the effeminate. According to historian Katherine Foxhall, although healthcare professionals did not determine that migraine occurred with more frequency in women until the twentieth century, healthcare professionals began to delineate migraine as a feminine problem as early as the nineteenth century [23]. The thought at that time was that exhaustion of childbirth, domestic anxieties, and thinking (an activity discouraged in women) could generate migraine.

Harold G. Wolff, whose scientific experiments demonstrated the somatic basis of migraine and launched modern headache medicine, popularized the idea that migraine affected a particular kind of person, who could be identified by their "migraine personality." Wolff described men who had a migraine personality in positive terms; men with migraine were ambitious, hard-working, and detail-oriented. However, these qualities were not described positively when applied to women, as their ambitions and attention to detail were derided and belittled as a neurotic focus on housework and inappropriate nagging of their husbands [22•].

Overall, historical analyses demonstrate that representations of migraine have remained remarkably steady over the last 300 years, even as the status of women and treatments for migraine dramatically improved. Alexander Pope's early eighteenth-century Rape of the Lock, which mocks the vanities and idleness of high society, features the protagonist lying in bed with a megrim as she mourned the loss of her favorite lock of hair. Contemporary images, including those from pharmaceutical advertisers, represent migraine as something that happens to White women in full make-up with fingers pressed to their temples [22•]. Children, when shown, are props, placed in the background to demonstrate that women with migraine cannot nurture their children properly [22•]. Medications and trigger avoidance are represented as easy ways to stop migraine in its tracks. Even style magazines stigmatize migraine, as demonstrated in 2018 when one fashion editor suggested that women could appear glamourous in their photos by striking the "migraine pose," depicted as celebrities and women touching the tips of their fingers to their forehead [24]. Taken together, media coverage creates the impression that migraine is an easily solved lifestyle disorder that happens to White, wealthy women who can afford to lie in bed.

Media representations create stigma for all people with migraine but may cause particular harm to those who are 
rendered invisible by the hypervisibility of White, middleclass women. Widely broadcast messages that migraine is easy to treat with medication ignore those who cannot access proper care, or who require expensive drugs and/or hospital admissions, or for whom available drugs are contraindicated. Non-White people will not see themselves in contemporary representations of migraine. And, although migraine is more prevalent among men than prostate disease or diabetes, women are up to four times more likely to be portrayed as a person with migraine in pharmaceutical depictions of people with migraine [25].

Aside from the cultural analyses articulated above that link migraine stigma to its association with women and feminized weakness, migraine shares with other stigmatizing diagnoses some characteristics that may make it particularly vulnerable to stigma. For example, like mental illness, addiction, and other many pain disorders, migraine is invisible and cannot be measured or confirmed by an objective diagnostic test. Compared to epilepsy, which has a physical manifestation, people with chronic migraine are viewed as less trustworthy, less likely to try their hardest, and more likely to malinger $[6,26]$.

Migraine might also be vulnerable to stigma because, like depression, autism, and asthma, and other pain disorders, it is a spectrum disease. People diagnosed with migraine may have a single attack a year or multiple attacks per week. Paradoxically, individuals who experience milder symptoms on this spectrum may actually predispose them to stigmatize, rather than empathize, those with more severe symptoms. One individual may discount another individual's experience with migraine or another primary headache disease by not understanding that the disease can differ in severity, symptomatology, or responsiveness to specific treatments $[27,28 \bullet]$.

Stigmatizing attitudes have a direct impact on workplace productivity and well-being. In a study specifically assessing stigmatizing attitudes toward migraine, Shapiro et al. [6] found that the following traits correlated with more stigmatizing attitudes (in order of effect size): male, non-White, younger, not having migraine, greater fear of pain, reduced empathy, reduced fear of migraine, and lower socioeconomic status. Educational attainment did not correlate with stigmatizing attitudes [6]. In subjects given vignettes about people with migraine, there was a gradient of stigmatizing attitudes toward people who missed work due to migraine (10 days/per year more than 2 days/year more than 0 days per year) [6]. In an epidemiological study of 9999 persons without migraine, he found that $31 \%$ believe that persons use their migraine as a way to get out of work or school commitments sometimes, often, or very often, $45 \%$ believe they should be easily able to treat their migraine, and $36 \%$ believe migraine is a result of their unhealthy behaviors [29]. Subjects who knew multiple people with migraine tended to hold more negative attitudes toward people with the disease. The authors speculated this might be explained by the burden of the migraine on family, friends, and coworkers. The consequences of this type of stigma in the workplaces can inadvertently lead to presenteeism that results in daily productivity loss in addition to poor well-being [30]. In addition, psychosocial stressors perceived in the workplace can in themselves lead to sickness absence and burnout [31].

\section{Structural Stigma}

The effects of public structural stigma can be more easily quantified. Public stigma is transformed into discriminatory structural policies, practices, and organizational culture. Examples of how structural stigma disadvantages migraine abound, but arguably none are so consequential as the consistently low levels of funding that migraine and other headache disorders receive from the National Institutes of Health (NIH) relative to its disease burden [2]. For example, in 2009, headache disease research warranted more than $\$ 103$ million/year relative to disease burden but only received \$6.8-\$13 million/year [2]. Lack of federal support for research on headache disorders has multiple ramifications. Less funding for basic research likely means fewer therapeutic innovations. In addition, this lack of federal funding may lower the social status of headache medicine subspecialists as compared to other medical colleagues-a pernicious form of "courtesy stigma."

Structural stigma may also explain low help-seeking rates among those with migraine, as well as the low standard of care for those who do seek help. More than $50 \%$ of all patients with migraine report episodes of severe impairment [32]. Nonetheless, access to early headache management and preventive treatment is limited in the USA, Europe, and developing countries [4, 33, 34]. In the USA, less than half of patients with episodic or chronic migraine consulted healthcare professionals for a primary headache disorder, with less than half of these patients being treated with preventive pharmacological agents [32, 33, 35, 36]. Care for chronic migraine is worse: only $5 \%$ of those with chronic migraine have received a correct diagnosis and recommended treatment [35]. The Eurolight study, surveying 10 European countries, found that a range of $15-26 \%$ of patients in the general population consult healthcare professionals for migraine, with only $2-6 \%$ eligible patients receiving preventive treatment [37]. Care often occurs after a delay of several years [37]. In Ethiopia, 92\% of people with primary headache disorders in a community survey did not receive professional health care and none were given preventive therapy [38].

Although insurance status is the largest predictor of help-seeking behavior in the USA, structural stigma can 
help explain the extraordinary low levels of care that those with migraine receive $[33,35]$. For example, structural stigma explains why patients so often find it difficult to locate healthcare professionals adequately trained in headache medicine. Access to headache medicine specialists is limited by volume; currently, there are only 570 physician diplomats certified in Headache Medicine [39]. In addition, formal headache medicine education during medical school and residency varies greatly [40]. In a survey of 195 medical institutions, only $29 \%$ of departmental chairs or residency program directors agreed or strongly agreed that headache diagnosis and management was adequately taught [41]. Lack of knowledge of appropriate migraine diagnosis and management may explain why so many people with migraine are often misdiagnosed in the clinic.

Stigma likely also degrades the quality of care that migraine patients receive. People with migraine often describe having had negative, and sometimes stigmatizing, experiences with healthcare professionals. These negative experiences might create "treatment carryover," a phenomenon that occurs when people forego medical treatment rather than risk having a negative experience in the clinic [21]. For example, research has demonstrated how treatment carryover suppresses help-seeking among patients with migraine and comorbid psychiatric symptoms. In one study, patients with migraine were found to have higher levels of psychiatric symptoms when compared to healthy individuals; however, only a minority of these individuals received psychiatric support [42]. In addition, patients with migraine and a high level of psychiatric symptoms had higher social stigma scores when compared to patients with a low level of symptoms [42]. The study postulated that negative perceptions about individuals with stigmatized disorders affect individuals in need of treatment because they fear stigmatization, which could lead to suppression of stigmatized concerns, in this case psychiatric symptoms, and avoidance of treatment [42]. Similar dynamics might be at play in the migraine population as a whole. Results from the Migraine Knowledge, Attitude, and Practice Patterns (MKAPP) Survey, which assessed the attitudes of neurologists toward migraine, found that nearly a third of neurologists disagreed or did not respond to the notion that migraine is a legitimate brain disease [43].

Structural stigma reduces access to care, which, in turn, contributes to delays in diagnosis and high rates of misdiagnosis. Even when a diagnosis is given, patients may still not be given appropriate treatment. Even when treatment is prescribed, it may not be accessible. Together, these factors perpetuate the disability associated with the disease. More research needs to investigate how structural stigma affects help-seeking and the clinical encounter (Table 1).

\section{Internalized Stigma}

Individuals with a stigmatized disease, such as migraine, internalize adverse attributes attached to the disease by society, resulting in the application of this stigma toward their self-perception and their disease. Internalized stigma can have profound effects on how individuals with migraine and other primary headache disorders view themselves and their quality of life. This concept was demonstrated in a large clinic-based study using the Stigma Scale for Chronic Illness (SSCI-24) to objectively measure internalized and enacted stigma in patients with chronic migraine, episodic migraine, and epilepsy [8•]. Results showed that patients with chronic migraine felt more stigmatized than patients with episodic migraine or epilepsy, who noted similar amounts of perceived stigma. Work-related disability was an important factor correlation with enacted and internalized stigma. Once this factor was removed, patients with chronic migraine had similar SSCI scores to those with epilepsy. Using a 12-item Short-Form Health Survey (SF-12), researchers also demonstrated that people with chronic migraine had a lower perceived quality of life as compared to people with epilepsy or episodic migraine [8•]. This study highlights the impact of internalized stigma on quality of life as well as the potential power of workplace accommodations to alleviate internalized stigma.

Research also indicates that internalized stigma itself has a corrosive effect on the health of those who experience

Table 1 Types and examples of stigma

\begin{tabular}{lll}
\hline Type of stigma & Definition & Migraine specific examples \\
\hline Structural & $\begin{array}{c}\text { Prejudice and discrimination by policies, laws, and consti- } \\
\text { tutional practice }\end{array}$ & $\begin{array}{l}\text { No "blue book" listing for SSDI } \\
\text { Worst ratio of NIH funding to disease impact of all } \\
\text { tracked diseases } \\
\text { "It's just a headache" } \\
\text { "I get migraine, and I can do that" }\end{array}$ \\
Self-stigma = internalized & $\begin{array}{l}\text { Stereotypes, prejudice and discrimination } \\
\text { Shame, low self-esteem, lack of engagement in treatment }\end{array}$ & $\begin{array}{l}\text { Not seeking a diagnosis, or treatment } \\
\text { Negative self-talk }\end{array}$ \\
Extension of prejudice and discrimination to people who & $\begin{array}{c}\text { Lower social status of headache medicine specialists as } \\
\text { compared to colleagues in other medical fields }\end{array}$ \\
\hline
\end{tabular}


pain. A systematic review and thematic analysis of the perceived experiences of people with chronic headache disorders showed that a perceived loss of control due to their disease significantly contributed to psychological stress [44]. Another study using data from the National Survey of Midlife Development in the United States (MIDUS), a longitudinal panel of US adults compiled since 1995, found that psychological distress due to perceived discrimination can exacerbate chronic pain [45]. MIDUS data scales of lifetime perceived discrimination and daily perceived discrimination, which include questions on workplace, medical, and individual discrimination that are relevant to migraine and other primary headache disorders, which were analyzed from three time points: 1995-1996, 2004-2005, and 2013-2014. The analysis showed that (1) variation in psychological distress was due to variations in discrimination and that [2] there is a causal effect of psychological distress on chronic pain [45]. This study is noteworthy in demonstrating that perceived discrimination (which we equate to internalized stigma) can directly worsen chronic pain. These studies also align with a robust literature on internalized stigma's corrosive effect on health [46]. More research can clarify how the internalized stigma of migraine impacts those with the disease.

\section{Migraine Stigma Is Pervasive}

The stigma of migraine extends far beyond healthcare, weaving its way in multiple dimensions of life. In the workplace, stigma is structural and enacted. In the USA, employees with migraine receive few accommodations despite the fact that migraine disability is covered under the Americans with Disabilities Act. Migraine costs an estimated 197 billion dollars per year to employers and is a major cause of reduced productivity and absenteeism [47]. However, at least one study indicates that much of this disability might be better attributed to "difficulties in work-related activities," rather than more frequent and painful headaches [3]. Simple accommodations, for example, modifications regarding computer work, lighting, or noise and odor exposure, could reduce disability and are already mandated by the ADA [48]. Nevertheless, obtaining supervisor for support for migraine accommodations in the workplace can be difficult [49].

Structural stigma can also be found written directly into the Social Security Blue Book, which has-to dateexcluded migraine or headache disorders from neurological categories listed as eligible for social security disability benefits [50]. Long-term disability benefits are often difficult to obtain, but this gap in coverage creates an additional burden for those disabled by migraine. Long-term disability benefits can take up to 3 years to obtain, with only $17 \%$ of initial headache disease claims allowed by the Social Security administration $[48,51]$.
Structural stigma can lead to a detrimental cycle of disability for individuals with migraine and other headache disorders. Lack of research funding leads to a lack of effective treatments, thereby leading to increased disability. Lack of NIH funding contributes to disinterest in establishing expertise within academic neurology leading to little interest among neurology and primary care residencies. Workplace accommodations that could alleviate this disability are limited. Then, when faced with the burden of disease incurred by migraine, structural support fails by making long-term disability benefits largely inaccessible. Ironically, the system is organized in such a way that its failure is framed and experienced as an individual problem, making it all the more likely than those with migraine will internalize their inability to work as a personal failure, rather than as a social problem.

\section{Interventions to Reduce Stigma}

Stigma directly diminishes the lives of those with migraine, exacerbating symptoms, decreasing quality of life, and creating obstacles for those seeking care and accommodations. It is clear that there is an urgent need for interventions to reduce migraine and headache-related stigma.

Anti-stigma strategies for medical conditions are typically grouped into three categories: [1] education, [2] contact, and [3] protest [52]. However, what is not known is the extent to which these interventions will actually produce the desired result of alleviating headache-related stigma $[53,54 \bullet]$.

To this end, in 2019, the Coalition of Headache and Migraine Patient (CHAMP) organized a symposium for migraine patient advocacy leaders, headache specialists, researchers, communicators, and industry partners to learn from academic and practical experts on disease stigma in other fields. Discussion at this symposium underscored the issue that outcomes of anti-stigma programs should be closely monitored as efforts may inadvertently exacerbate the very stigma they seek to eradicate. While the conclusive White paper from this coalition is still pending, a resulting key takeaway point is that the development and implementation of stigma intervention programs ought to be evidencebased and results should be monitored. This review will therefore take a closer look at known anti-stigma strategies and their application for reducing migraine and headacherelated stigma.

\section{Education}

Public educational programs are knowledge-based interventions used to target inaccurate stereotypes by replacing them with facts. For example, an educational program may challenge the idea that migraine is "just a bad headache" 
with education regarding the complexity of the condition and range of symptoms that can accompany headache pain. Education has many advantages; it is cost-effective and captures a wide audience [11]. Public education programs can be distributed through a variety of means, including movies, books, public service announcements, websites, and videos, among others [11]. Blogs, such as those by the American Migraine Foundation, and documentaries, such as "Out of My Head," are examples of educational programs that exist for migraine [55, 56]. In the USA, Miles for Migraine, the World Headache Summit, and the Migraine Research Foundation are examples of groups that have launched educational initiatives to improve public understanding of migraine and other primary headache disorders. Internationally, Lifting the Burden, the World Headache and Migraine Alliance, the Migraine Trust, and International Headache Society/Global Patient Advocacy Coalition are more examples of organizations who aim to relieve stigma by providing educational resources.

There is evidence that education can significantly improve attitudes toward stigmatized diseases [11]; however, continued educational efforts should consider lessons learned from anti-stigma campaigns in other fields. For example, in 1999, the USA began to systematically pursue anti-stigma campaigns for mental illnesses in order to increase public support for services. A chief message, predicated on an assumption that emphasizing the neurobiology of mental illnesses decreased stigma, defined mental illness as biological medical disease or "brain disorder." However, follow-up studies on the impact of this campaign on stigma showed that while blame decreased, public stigma toward depression remained unchanged, and stigma toward schizophrenia actually worsened $[57,58]$. The neurobiological model gave the public the impression that people will not recover [57]. This consequence of an anti-stigma effort underscores the need for close monitoring of educational initiative outcomes, as assumptions regarding public perception can be misleading.

\section{Contact}

Contact, or interaction between individuals of the general population and of the stigmatized disease, is another antistigma strategy. Contact has shown to yield even more improvement in attitudes than education in outcome studies pertaining to mental illness $[11,54 \bullet]$. Specifically, community, or grassroots, is important; grassroots contact has been shown to carry twice as much impact as population-based contact (for example, video-taped or social marketing). In addition, advocates can maintain control in grassroots movements, as opposed to the control of adverting consortia and governmental operations in population-based contact [54•].

Grassroots contact can be done through advocacy groups that interface with communities and policymakers. For example, Miles for Migraine is an organization that hosts events to promote community contact, such as communitybased races or educational programs. Headache on the Hill, led by the Alliance for Headache Advocacy Disorders (AHDA), is another type of program that allows patients with primary headache disorders, clinicians, and other advocates the ability to personally speak with members of Congress and advocate for structural support. Based on outcomes from the mental health anti-stigma campaign, opportunities for face-to-face contact should be emphasized $[11,54 \bullet]$. However, given the potential impact public acknowledge of migraine may have on professional and personal relationships, it does take courage for people to self-identify as someone with disabling migraine should be acknowledged $[28 \bullet]$.

Importantly, further research is needed to ascertain both negative and positive factors that influence stigma reduction during intergroup contact as the consequences of the outcome are not always clear [53]. For example, anti-stigma efforts for mental illness resulted in increased pity, which has both good (increased allocation funds for mental health services) and bad (benevolent stigma) effects [54•, 57, 59].

\section{Protest}

Protest efforts call against injustices caused by stigma and shame offenders for discrimination. These strategies, while changing "politically correct" representations and speech, do have the potential to backfire. One study found that forced suppression of stereotypes can actually have a "rebound" effect and increase stereotype activation [60]. Protest approaches to migraine stigma should therefore be approached with caution [57].

\section{Physician and Healthcare Professional Impact}

Mitigating negative societal attitudes toward people with primary headache disorders requires a multifactorial approach that ties in healthcare professionals. There is a need to expand access to medical professionals with expertise in headache medicine, so that people with migraine can receive a timely diagnosis [61]. Headache medicine education ought to be expanded across specialties and clinical professions and included as part of Continuing Medical Education courses, so that any healthcare professional likely to encounter an individual with a primary headache disorder will be capable of diagnosis and basic treatment [61].

Additional research might investigate how medical professionals might further reduce the stigma of headache disorders after diagnosis. One possible intervention may be 
to deemphasize the role of managing "triggers" and medication "overuse" (using the term medication adaptation instead) when counseling patients [62•, 63•]. Emphasizing a patient's own behavior results in a migraine attack encourages patients to blame themselves every time they have a migraine attack. In the field of oncology, self-blame has been shown to significantly exacerbate internalized stigma [64].

In addition, based on the strong positive correlation between disability and stigma, healthcare professionals need to acknowledge and reinforce the normality of migrainerelated disability. Unsupportive and negative attitudes by healthcare professionals toward patients with work or other disabilities may increase internalized stigma. Messages of empowerment and self-determination rather than pity have been found to be the best approach against stigma [57]. To that end, healthcare professionals can help patients continue work by providing support for accommodations in the workplace. Awareness on how to secure workplace accommodations through the Americans with Disabilities Act could help those with a severe primary headache disorder continue to work [65]. In addition, there needs to be continued advocacy for the inclusion of primary headache disorders as a neurological category for Social Security disability benefits for those who cannot work. The use of terms such as "discrimination" when referring to stigma may help enable access to the structural support that is available.

Finally, healthcare professionals also play a pivotal role in reframing the language used surrounding migraine. While re-wording a disease alone has not been found to be helpful against stigma toward mental illness, language does play a role in stigma and discrimination [57]. The language currently used colloquially and in migraine literature contributes to the negative connotation of the disease. Frequently, people with migraine are referred to as "migraineurs"; terminology which depicts patients with migraine as a specific, distinct group of people, differing from the norm with their whole identity comprised solely of the disease [63•]. Terms such as "migraines" or "migraine headaches" undermine the chronic and diverse features of migraine when used to define migraine disease as a whole [63•]. The Coalition for Headache and Migraine Patients (CHAMP) has recently published the patient lexicon establishing what words patients prefer the public and the medical community to use [62•] (Table 2).

\section{Further Research}

Migraine is a challenging disease to destigmatize due to both its internal variability and invisibility of disease characteristics and the impact social environment has on causing variable degrees of disability among people with similar degrees of the disease. Migraine is a disease with individual variability in severity and symptoms; one's perception of migraine cannot be applied to everyone with migraine. Because of these complexities, it is difficult to correctly educate the public. The invisibility of the symptoms of migraine, including pain, sensory sensitivity, and neurocognitive difficulties, makes contact strategies harder to implement than for other diseases. The social context in which migraine is present (for example, at work, or with family) varies and affects the amount of disability rendered by migraine and stigma. The self-employed individual who has work flexibility can be more successful at managing their migraine disease than the individual with no work flexibility or accommodations. Meanwhile, people for whom migraine is more debilitating may not be physically able to participate in contact advocacy. While there are interventions in place to mitigate negative societal attitudes toward people with primary headache disorders, further research needs to be done regarding their effectiveness [66].

Objective measurements of increasing structural support, such as NIH funding, could be one means of gauging the impact of anti-stigma strategies. Enacted stigma, which may evolve over time, may be more difficult to assess. Continued

Table 2 Anti-stigma language recommendations

\begin{tabular}{ll}
\hline Language & \\
\hline CHAMP recommendation & Currently used \\
\hline Headache disease(s), headache disorders(s) & Headache(s) \\
Headache attack, migraine attack, cluster attack & Headache(s), migraine(s), episode(s) \\
Migraine disease, living with migraine disease & Migraine headache, migraines \\
Person with migraine disease, person living with migraine disease & Migraine personality, migraineur, migrainer, \\
migraine person, migraine-type person
\end{tabular}


assessments of attitudes toward primary headache disorders are needed through longitudinal population-based surveys or interval measurements of patients' experience with stigma and discrimination.

There is also much we still do not know about how stigma impacts those in marginalized populations. For example, research has primarily been done in White populations with access to insurance, but we know little about the role of stigma in the health care experience of low-income populations or among those of different races and ethnicities with primary headache disorders [67]. Further research is needed on how to conceptualize the stigma of headache disorders in populations where there are co-existing stigmatizing conditions; for example, in populations who have experienced domestic abuse, or in obese populations [46, 68]. Understanding these factors could help make access to effective care and treatment more widely available to individuals with primary headache disorders.

Finally, another area of future research on stigma is pediatric migraine stigma, which has not been studied. How and when do children with migraine first experience its stigma? How do kids without migraine or other stigmatizing attitudes develop them? What interventions will reduce migraine stigma and improve empathy?

Interestingly, the COVID-19 pandemic may offer some insight into migraine stigma and interventions [28•]. For example, it will enable us to see if a flexible workfrom-home environment is beneficial for patients with migraine. It will also shed light on how social inequities have a direct impact on the outcomes of diseases, such as migraine (69).

People with migraine deserve to be free of discriminatory policies and stigmatizing public attitudes and receive adequate structural support. A deeper understanding of stigma toward migraine will help accomplish this goal.

Supplementary Information The online version contains supplementary material available at https://doi.org/10.1007/s11916-021-00982-z.

\section{Compliance with Ethical Standards}

Conflict of Interest Joanna Kempner reports personal fees from Miles for Migraine and from Amgen, outside the submitted work.

Simy Parikh reports personal fees from Allergan and partial salary support from a Teva educational grant, outside the submitted work. William Young reports grants and personal fees from Allergan, Eli Lilly, Teva; grants from Cumberland, Novartis, PCORI, Zosano, Promius, Colucid, Dr. Reddy Labs, Alder, Biohaven, Theranica, Charleston Labs, Electrocore, and Satsuma; and is an Advising Physician and Chairman of the Board for the Coalition for Headache and Migraine Patients (CHAMP) and serves as president for Miles for Migraine and Co-Medical Direcctor of Ctrl M Health.

Human and Animal Rights and Informed Consent This article does not contain any studies with human or animal subjects performed by any of the authors.

\section{References}

Papers of particular interest, published recently, have been highlighted as:

- Of importance

1. Vos T, Allen C, Arora M. Global regional and national incidence prevalence and years lived with disability for 310 diseases and injuries, 1990-2015: a systematic analysis for the Global Burden of Disease Study 2015. Lancet. 2016;388(10053):1545-602.

2. Schwedt TJ, Shapiro RE. Funding of research on headache disorders by the National Institutes of Health. Headache: The Journal of Head and Face Pain. 2009;49(2):162-169.

3. D'Amico D, Grazzi L, Curone M, Di Fiore P, Proietti Cecchini A, Leonardi M, et al. Difficulties in work activities and the pervasive effect over disability in patients with episodic and chronic migraine. Neurol Sci. 2015;36(Suppl 1):9-11.

4. Katsarava Z, Mania M, Lampl C, Herberhold J, Steiner TJ. Poor medical care for people with migraine in Europe - evidence from the Eurolight study. J Headache Pain. 2018;19(1):10.

5. Minen MT, Anglin C, Boubour A, Squires A, Herrmann L. Metasynthesis on migraine management. Headache. 2018;58(1):22-44.

6. Shapiro RE, Lipton RB, Reiner PB. EHMTI-0313. Factors influencing stigma towards persons with migraine. J Headache Pain. 2014;15(S1):E36.

7. Aydemir N, Ozkara C, Unsal P, Canbeyli R. A comparative study of health related quality of life, psychological well-being, impact of illness and stigma in epilepsy and migraine. Seizure. 2011;20(9):679-85.

8. Young WB, Park JE, Tian IX, Kempner J. The stigma of migraine. PLoS One. 2013;8(1):e54074. Of importance: Study investigating the extent to which stigma is attached to migraine.

9. Clair M, Daniel C, Lamont M. Destigmatization and health: cultural constructions and the long-term reduction of stigma. Soc Sci Med. 2016;15(165):223-32.

10. Sirey JA, Bruce ML, Alexopoulos GS, Perlick DA, Friedman SJ, Meyers BS. Stigma as a barrier to recovery: perceived stigma and patient-rated severity of illness as predictors of antidepressant drug adherence. Psychiatr Serv. 2001;52(12):1615-20.

11. Corrigan PW, Morris SB, Michaels PJ, Rafacz JD, Rüsch N. Challenging the public stigma of mental illness: a meta-analysis of outcome studies. Psychiatr Serv. 2012;63(10):963-73.

12. Watson AC, Corrigan P, Larson JE, Sells M. Self-stigma in people with mental illness. Schizophr Bull. 2007;33(6):1312-8.

13. Jacoby A, Snape D, Baker GA. Epilepsy and social identity: the stigma of a chronic neurological disorder. Lancet Neurol. 2005;4(3):171-8.

14. Grytten N, Måseide P. When I am together with them I feel more ill. ' The stigma of multiple sclerosis experienced in social relationships. Chronic Illn. 2006;2(3):195-208.

15. Farrugia D. Exploring stigma: medical knowledge and the stigmatisation of parents of children diagnosed with autism spectrum disorder. Sociol Health Illn. 2009;31(7):1011-27.

16. Milne A. The "D" word: reflections on the relationship between stigma, discrimination and dementia. J Mental Health. 2010;19(3):227-33.

17. Schneider J, Conrad P. In the closet with illness: epilepsy, stigma potential and information control. Soc Probl. 1980;32-42.

18. Shostak S, Fox NS. Forgetting and remembering epilepsy: collective memory and the experience of illness. Sociol Health Illn. 2012;34(3):362-78.

19. Goffman E. Stigma: notes on the management of spoiled identity. New York: Simon and Schuster; 1963. 
20. Link BG, Phelan JC. Conceptualizing stigma. Annu Rev Sociol. 2001;27(1):363-85.

21. Pescosolido BA, Martin JK. The stigma complex. Annu Rev Sociol. 2015;41:87-116.

22. Kempner J. Not tonight: migraine and the politics of gender and health. Chicago: The University of Chicago Press; 2014. Of importance: provides historical and current concepts on pervasive gendered social values and their influence on policies for people in pain.

23. Foxhall K. Migraine: A history. Baltimore: Johns Hopkins University Press. 2019.

24. Instagram "migraine pose" is causing backlash Internet. 2019. Available from: https://www.today.com/style/instagram-migrainepose-causing-backlash-t133158.

25. Kempner J. Gendering the migraine market: do representations of illness matter? Soc Sci Med. 2006;63(8):1986-97.

26. Shapiro RE, Reiner PB. Stigma towards migraine. Cephalalgia. 2013;33(Suppl. 8):17.

27. Lonardi $\mathrm{C}$. The passing dilemma in socially invisible diseases: narratives on chronic headache. Soc Sci Med. 2007;65(8):1619-29.

28. Shapiro RE. What will it take to move the needle for headache disorders? an advocacy perspective. Headache. 2020;60(9):20592077. Of outstanding importance: details AHDA efforts to address discriminatory policies of employers, government agencies, and public institutions.

29. Shapiro RE, Araujo AB, Nicholson RA, Reed ML, Buse DC, Ashina S, et al. OR15: Stigmatizing attitudes about migraine by people without migraine: results of the OVERCOME study. Headache: The Journal of Head and Face Pain. 2019

30. Allen D, Hines EW, Pazdernik V, Konecny LT, Breitenbach E. Four-year review of presenteeism data among employees of a large United States health care system: a retrospective prevalence study. Hum Resour Health. 2018;16(1):59.

31. Aronsson V, Toivanen S, Leineweber C, Nyberg A. Can a poor psychosocial work environment and insufficient organizational resources explain the higher risk of ill-health and sickness absence in human service occupations? Evidence from a Swedish national cohort. Scand J Public Health. 2019;47(3):310-7.

32. Lipton RB, Bigal ME, Diamond M, Freitag F, Reed ML, Stewart WF, et al. Migraine prevalence, disease burden, and the need for preventive therapy. Neurology. 2007;68(5):343-9.

33. Lipton RB, Serrano D, Holland S, Fanning KM, Reed ML, Buse DC. Barriers to the diagnosis and treatment of migraine: effects of sex, income, and headache features. Headache. 2013;53(1):81-92.

34. Woldeamanuel YW, Andreou AP, Cowan RP. Prevalence of migraine headache and its weight on neurological burden in Africa: a 43-year systematic review and meta-analysis of community-based studies. J Neurol Sci. 2014;342(1-2):1-15.

35. Dodick DW, Loder EW, Manack Adams A, Buse DC, Fanning $\mathrm{KM}$, Reed ML, et al. Assessing barriers to chronic migraine consultation, diagnosis, and treatment: results from the chronic migraine epidemiology and outcomes (cameo) study. Headache. 2016;56(5):821-34.

36. Minen MT, Anglin C, Boubour A, Squires A, Herrmann L. Meta-synthesis on migraine management. Headache: The Journal of Head and Face Pain. 2018;58(1):22-44.

37. Tassorelli C, Farm I, Kettinen H, de la Torre ER, Stretenovic S, Thomas W, et al. Access to care - an unmet need in headache management? J Headache Pain. 2014;15(1):20.

38. Mengistu G, Alemayehu S. Prevalence and burden of primary headache disorders among a local community in Addis Ababa, Ethiopia. J Headache Pain. 2013;28(14):30.

39. Diplomate Directory Internet. 2019. Available from: https:// www.ucns.org/Online/Diplomate_Directory/Online/Diplomate_ Directory.aspx?hkey=f8f00552-f924-4ef6-a9bb-6023b1cd341b
40. Gallagher RM, Alam R, Shah S, Mueller L, Rogers JJ. Headache in medical education: medical schools, neurology and family practice residencies. Headache. 2005;45(7):866-73.

41. Kommineni M, Finkel AG. Teaching headache in America: survey of neurology chairs and residency directors. Headache. 2005;45(7):862-5.

42. Korkmaz S, Kazgan A, Korucu T, Gönen M, Yilmaz MZ, Atmaca M. Psychiatric symptoms in migraine patients and their attitudes towards psychological support on stigmatization. J Clin Neurosci. 2019;62:180-3.

43. Lipton RB, Bigal ME, Rush SR, Yenkosky JP, Liberman JN, Bartleson JD, et al. Migraine practice patterns among neurologists. Neurology. 2004;62(11):1926-31.

44. Nichols VP, Ellard DR, Griffiths FE, Kamal A, Underwood M, Taylor SJC, et al. The lived experience of chronic headache: a systematic review and synthesis of the qualitative literature. BMJ Open. 2017;7(12):e019929.

45. Brown TT, Partanen J, Chuong L, Villaverde V, Chantal Griffin A, Mendelson A. Discrimination hurts: the effect of discrimination on the development of chronic pain. Soc Sci Med. 2018;8(204):1-8.

46. Livingston JD, Boyd JE. Correlates and consequences of internalized stigma for people living with mental illness: a systematic review and meta-analysis. Soc Sci Med. 2010;71(12):2150-61.

47. Linde M, Gustavsson A, Stovner LJ, Steiner TJ, Barré J, Katsarava $\mathrm{Z}$, et al. The cost of headache disorders in Europe: the Eurolight project. Eur J Neurol. 2012;19(5):703-11.

48. Borkum J, Evans RW. Disability and chronic migraine. Headache: The Journal of Head and Face Pain. 2014;54(4):719-725.

49. Employees hide headaches, migraines from supervisors. Internet. 2018. Available from: https://www.reuters.com/ brandfeatures/excedrin/employees-hide-headaches-migrainesfrom-supervisors

50. 11.00-Neurological-Adult Internet. 2019. Available from: https://www.ssa.gov/disability/professionals/bluebook/11.00Neurological-Adult.htm.

51. Meseguer J. Correlation patterns between primary and secondary diagnosis codes in the social security disability program [Internet]. Social Security Office of Retirement and Disability Policy. 2018. Cited 2019 Aug 2. Available from: https://www.ssa.gov/ policy/docs/workingpapers/wp113.html.

52. Corrigan PW, River LP, Lundin RK, Penn DL, Uphoff-Wasowski $\mathrm{K}$, Campion J, et al. Three strategies for changing attributions about severe mental illness. Schizophr Bull. 2001;27(2):187-95.

53. Pettigrew TF, Tropp LR. A meta-analytic test of intergroup contact theory. J Pers Soc Psychol. 2006;90(5):751-83.

54. Corrigan PW, Fong MWM. Competing perspectives on erasing the stigma of illness: what says the dodo bird? Soc Sci Med. 2014;103:110-117. Of importance: review of outcomes from antimigraine strategies for mental illnesses.

55. The true pain of migraine misconceptions I American Migraine Foundation Internet. Cited 2019 Oct 10. Available from: https:// americanmigrainefoundation.org/resource-library/the-true-painof-migraine-misconceptions/.

56. Out of My Head - Trailer - Migraine. It's not just a headache. Internet. Cited 2019 Oct 10. Available from: https://outofmyheadfilm. com.

57. Corrigan PW. Lessons learned from unintended consequences about erasing the stigma of mental illness. World Psychiatry. 2016;15(1):67-73.

58. Phelan JC, Cruz-rojas R, Reiff M. Genes and stigma: the connection between perceived genetic etiology and attitudes and beliefs about mental illness. Psychiatr Rehabil Skills. 2002;6(2):159-85.

59. Corrigan PW, Watson AC, Warpinski AC, Gracia G. Stigmatizing attitudes about mental illness and allocation of resources to mental health services. Community Ment Health J. 2004;40(4):297-307. 
60. Macrae CN, Bodenhausen GV, Milne AB, Jetten J. Out of mind but back in sight: Stereotypes on the rebound. J Pers Soc Psychol. 1994;67(5):808-17.

61. Dodick D, Edvinsson L, Makino T, Grisold W, Sakai F, Jensen $\mathrm{R}$, et al. Vancouver declaration on global headache patient advocacy 2018. Cephalalgia. 2018;38(13):1899-909.

62. CHAMP releases headache and migraine disease language and image guide - coalition for headache and migraine patients Internet. Cited 2019 Oct 16. Available from: https://headachemigraine.org/ champ-releases-headache-and-migraine-disease-language-andimage-guide/. Of outstanding importance: provides language and image modifications to reduce stigma for patients with headache and migraine.

63. Young WB. De-stigmatizing migraine - with words. Headache. 2018;58(2):319-321. Of importance: provides language modifications to reduce stigma for patients with headache and migraine.

64. Else-Quest NM, LoConte NK, Schiller JH, Hyde JS. Perceived stigma, self-blame, and adjustment among lung, breast and prostate cancer patients. Psychol Health. 2009;24(8):949-64.
65. Shapiro RE. Migraine and disability rights. Continuum (Minneap, Minn). 2012;18(4):900-4.

66. American Migraine Foundation. Move against migriane Internet. Cited 2019 Aug 1. Available from: https://americanmigrainefoundation. org/move-against-migraine/.

67. Allen H, Wright BJ, Harding K, Broffman L. The role of stigma in access to health care for the poor. Milbank Q. 2014;92(2):289-318.

68. Pavlovic JM, Vieira JR, Lipton RB, Bond DS. Association between obesity and migraine in women. Curr Pain Headache Rep. 2017;21(10):41.

69. Chen JT, Krieger N. Revealing the unequal burden of COVID-19 by income, race/ethnicity, and household crowding: US county versus zip code analyses. J Public Health Manag Pract. 27 Suppl 1, COVID19 and Public Health: Looking Back, Moving Forward:S43-S56.

Publisher's Note Springer Nature remains neutral with regard to jurisdictional claims in published maps and institutional affiliations. 